\title{
Mesenchymal stem cells contribute to the chemoresistance of hepatocellular carcinoma cells in inflammatory environment by inducing autophagy
}

Zhipeng Han ${ }^{1+}$, Yingying Jing ${ }^{1 \dagger}$, Yong Xia ${ }^{2 \dagger}$, Shanshan Zhang ${ }^{1}$, Jing Hou', Yan Meng ${ }^{3}$, Fenghai Yu ${ }^{4}$, Xiaoqing Liu', Mengchao $\mathrm{Wu}^{1}$, Ping Zhang ${ }^{6}$ and Lixin Wei ${ }^{{ }^{*}}$

\begin{abstract}
Background: Mesenchymal stem cells (MSCs) have been reported to play an important role in tumor growth. Inflammation is an important feature of hepatocellular carcinoma (HCC). Certain inflammatory cytokines produced in tumor microenvironment modulate functional activities of MSCs. At the present time, however, the role of MSCs in the development of HCC cell resistance to chemotherapy in the inflammatory microenvironment during tumor growth has not yet been identified.
\end{abstract}

Methods: MTT and PI/Annexin V-FITC assay were employed to examine the proliferation and apoptosis of HCC cell lines. The expression of TGF- $\beta$ are detected by Realtime PCR and Western blot. GFP tagged LC3 expression vector and electron microscopy are utilized to demonstrate the occurrence of autophagy.

Results: We observed that MSCs pretreated with the combination of IFN- $\gamma$ and TNF-a induced resistance to chemotherapy in HCC cell lines in both the in vitro and in vivo circumstances. Following exposure to conditioned medium of MSCs that were pre-treated with IFN- $\gamma$ plus TNF-a, HCC cell line cells underwent autophagy which serves as a protective mechanism for HCC cells to resist the cell toxicity of chemotherapeutic agents. Treatment of HCC cell line cells with autophagy inhibitor effectively reversed the MSCs-induced resistance to chemotherapy in these cells. Stimulation with the combination of IFN- $\gamma$ and TNF- $a$ provoked expression of TGF- $\beta$ by MSCs. MSCs-induced chemoresistance in HCC cell lines was correlated with the up-regulation of TGF- $\beta$ expression by MSCs. Knockdown of TGF- $\beta$ expression by MSCs with siRNA attenuated MSCs-induced chemoresistance in HCC cells.

Conclusions: These results suggest that increase in TGF- $\beta$ expression by MSCs in the inflammatory microenvironment of HCC promotes the development of chemoresistance in HCC cells.

Keywords: Mesenchymal stem cells, Inflammation, Autophagy, Hepatocellular carcinoma

\section{Background}

Chemotherapy remains a major treatment alternatively to surgery for a large number of patients at the advanced stage of hepatocellular carcinoma (HCC). However, development of chemoresistance in HCC cells becomes a prominent obstacle for effective treatment of $\mathrm{HCC}$ with chemotherapy.

\footnotetext{
*Correspondence: lixinwei@smmu.edu.cn

${ }^{\dagger}$ Equal contributors

'Tumor Immunology and Gene Therapy Center, Eastern Hepatobiliary Surgery Hospital, the Second Military Medicial University, 225 Changhai Road, Shanghai 200438, China

Full list of author information is available at the end of the article
}

In addition to the chemoresistance originated from HCC cells themselves, accumulated evidences suggest that tumor microenvironment may also play an important role in inducing and/or promoting the development of drug resistance. Studies have shown that existence of certain specific properties of stromal cells is an indicator for poor prognosis [1]. Stromal cells may modulate the reaction of tumor cells to chemotherapy in various ways [2-5].

Mesenchymal stem cells (MSCs) have caught a wide attention in recent years because of their therapeutic potential to treat human diseases and their physiological 
roles in vivo [6,7]. MSCs are originally found in the bone marrow, but they have also been isolated from other sites in the body such as adipose tissue and uterus [8]. MSCs have the ability to differentiate into cells of multiple lineages including chondrocytes, osteocytes, adipocytes, myocytes, and astrocytes $[9,10]$. MSCs is positive for CD29, CD90 and CD105 and is negative for hematopoietic cell markers CD34 and CD45 [11]. MSCs express the major histocompatibility complex (MHC) class I but do not express MHC class II, B7-1, B7-2, CD40, or CD40L molecules. They can be expanded more than $10^{4}$-fold in culture without losing multilineage differentiation potential [12]. Therefore, MSCs are not only considered as an acceptable source of stem cells in hematopoietic recovery, but also an available cell type for tissue regeneration [9].

Interestingly, MSCs have the ability to migrate to tumor sites in different types of tumor models [13-15]. Inflammation is a common feature of the tumor microenvironment [16], which consists of cytokines, chemokines, and infiltrated leukocytes. MSCs may secrete several different types of mediators including interleukin-10 (IL-10) [17], transforming growth factor- $\beta$ (TGF- $\beta$ ) $[17,18]$, hepatocyte growth factor (HGF) [18], and vascular endothelial growth factor (VEGF) [19] when exposed to inflammatory cytokines, which has been reported to play an important role in tumor development.

In previous studies, we have demonstrated that MSCs in inflammatory environment may promote tumor growth via immunosuppression and angiogenesis. However, the role of MSCs in the development of chemoresistance in $\mathrm{HCC}$ cells in the inflammatory microenvironment during tumor growth remains unclear. The purpose of this study is to investigate the contribution of MSCs to development of chemoresistance in $\mathrm{HCC}$ cells and its potentially underlying mechanism.

\section{Methods \\ Reagents}

Recombinant human IFN- $\gamma$ (Cat. 300-02B) and TNF- $\alpha$ (Cat. 300-01A) were obtained from Peprotech (La Jolla, CA). Stock solutions of chemotherapeutic agents cisplatin (Qilu Pharmaceutical Co., Ltd., Jinan, Shandong, China, Cat.H20073653) and epirubicin (Pfizer Pharmaceuticals Limited, Wuxi, Jiangsu, China, Cat.H20093251) were prepared at the concentration of $1 \mathrm{mM}$, respectively. The stock solution of each agent was then added directly into cell culture media to achieve final concentrations as indicated in each figure legend in the "Results" section. Chloroquine (CQ, Cat.C6628) and 3-methyladenine (3-MA, Cat.M9281) were purchased from Sigma-Aldrich (St. Louis, MO).

\section{Culture of cell line cells}

Human MSCs (a gift from Institute of Health Sciences and Shanghai Institute of Immunology, Chinese Academy of Sciences, Shanghai, China) were cultured in Dulbecco's modified Eagle's medium (DMEM) nutrient mix F12 with fetal bovine serum (FBS, 10\%; Invitrogen, Cat. 10099-054). HCC cell line cells including SMMC-7721 cells and HepG2 cells were cultured in DMEM containing 10\% FBS. All cells were cultured at $37^{\circ} \mathrm{C}$ in a humidified atmosphere containing $5 \% \mathrm{CO}_{2}$.

\section{Generation of conditioned medium}

MSCs were stimulated with IFN- $\gamma(20 \mathrm{ng} / \mathrm{ml}), \mathrm{TNF}-\alpha$ $(20 \mathrm{ng} / \mathrm{ml})$ or both for $12 \mathrm{~h}$. The culture medium of MSCs was removed. Stimulated MSCs were cultured in fresh DMEM nutrient mix F12 for $24 \mathrm{~h}$. The conditioned medium in the MSC culture was then collected and filtered through a $0.22 \mu \mathrm{m}$ filter.

\section{Real-time RT-PCR}

MSCs were cultured with IFN- $\gamma(20 \mathrm{ng} / \mathrm{ml})$, TNF- $\alpha$ $(20 \mathrm{ng} / \mathrm{ml})$, or both for $12 \mathrm{~h}$. The cells were collected. Total mRNA was extracted from cells using the Trizol Reagent (Invitrogen, Carlsbad, CA, Cat.15596-026) and protocol provided by the manufacturer. Expression of TGF- $\beta$ mRNA was determined by real-time RT-PCR using the SYBR Green Master Mix Kit (Applied Biosystems, Foster City, CA, Cat.4306736) and protocol provided by the manufacturer. The amount of endogenous $\beta$-actin mRNA was used for normalization of TGF- $\beta$ mRNA expression in each sample. Primers for TGF- $\beta$ mRNA determination were: $5^{\prime}$-GCCGAGCCCTGGACACCAAC-3' (forward) and 5'-GCGCCCGGGTTATGCTGGTT-3' (reverse). Thermocycler conditions included an initial hold at $50^{\circ} \mathrm{C}$ for 2 minutes and then $95^{\circ} \mathrm{C}$ for 10 minutes, which was followed by a two-step PCR program of $95^{\circ} \mathrm{C}$ for 15 seconds and $60^{\circ} \mathrm{C}$ for 60 seconds repeated for 40 cycles on a Mx4000 system (Stratagene). Alteration of TGF- $\beta$ mRNA expression is presented as the fold change relative to an untreated control.

\section{MTT colorimetric assay}

To measure the effects of MSCs on chemosensitivity of human hepatoma cells, HCC cells were seeded in 96well plates at a density of $1 \times 10^{4}$ cells/well and cultured in the medium containing chemotherapeutic agents with or without MSCs conditioned medium for $8 \mathrm{~h}$. The cell viability in each well was examined by a MTT $(5 \mathrm{mg} / \mathrm{ml}$, Sigma-Aldrich, Cat.M2003) colorimetric assay. The optical density (OD) value at $490 \mathrm{~nm}$ of each sample was measured using a plate reader. All determinations were carried out in sextuplicate.

\section{Cell apoptosis assay}

HCC cells $\left(2 \times 10^{5}\right.$ cells/well $)$ were cultured in 6-well plates to $70-80 \%$ confluence. The cells were then treated with chemotherapeutic agents for $8 \mathrm{~h}$ in the absence and 
presence of MSC conditioned medium. In a subset of experiments, 3-MA (5 mM) was used to block autophagy. PI/Annexin V-FITC assay was used to measure apoptotic cells by flow cytometry according to the manufacturer's instruction (Keygen Biotech. Co., Ltd, Nanjing, Jiangsu, China, Cat.KGA108). Briefly, cells collected by trypsinization were washed trice with ice cold phosphate-buffered saline (PBS). Cells were then incubated in $300 \mu \mathrm{L}$ of $1 \times$ binding buffer containing $5 \mu \mathrm{L}$ Annexin V and $5 \mu \mathrm{L}$ PI for $30 \mathrm{~min}$ at room temperature in the dark. Apoptosis of cells was measured on a BD FACSAria flow cytometer (Becton Dickinson, Lincoln Park, NJ). At least 30,000 gated events were acquired from each sample. Results are expressed as the percentage of apoptotic cells (PI and Annexin $\mathrm{V}$ positive) in the gated cell population.

\section{Transient transfection and identification of autophagy}

GFP tagged LC3 expression vector has recently been utilized to demonstrate the occurrence of autophagy. SMMC-7721 and Hep3B cells were seeded $\left(1 \times 10^{4}\right.$ cells/ well) in 96-well plates overnight. GFP-LC3 expressing plasmids were transiently transfected into cells using the Fugene HD transfection reagent (Roche, NSW, Australia, Cat.04709705001) according to the manufacturer's instruction. After being cultured for $24 \mathrm{~h}$ to ensure expression of GFP-LC3, the cells were treated with MSC conditioned medium and cisplatin for $8 \mathrm{~h}$. In a subset of experiments, 3-MA was also added to the cell culture. At the end of each experiment, autophagy was detected by counting the number of cells with GFP-LC3-positive dots under fluorescence microscope (Olympus IX71). A minimum of 200 cells were counted in each sample. The experiment was conducted in triplicate.

\section{Electron microscopy}

HCC cells were sequentially fixed with $2.5 \%$ glutaraldehyde acid in 0.1 M PBS buffer ( $\mathrm{pH} 7.4)$ for $2 \mathrm{~h}$, incubated in $1 \%$ osmium tetroxide in $0.1 \mathrm{M}$ PBS buffer $(\mathrm{pH}$ 7.4) for 2-3 h, dehydrated in solutions of ethanol and acetone, embedded in Araldite, and finally solidified. Sections (50$60 \mathrm{~nm}$ ) were cut on a LKB-I ultramicrotome and picked up on copper grids. After being post-stained with uranyl acetate and lead citrate, sample sections were observed with a Philips CM-120 TEM (Philips).

\section{Animal model}

All procedures involving animals were performed in accordance with the institutional animal welfare guidelines of Second Military Medical University. Subcutaneous implantation of HCC cells (alone or mixed with MSCs) was performed in armpit areas of nude mice. Mice were examined three times per week. Tumor growth was evaluated by measuring the length and width of the tumor mass. Animals were sacrificed and tumors were removed at the end of the experiment. Tumor masses were weighed and analyzed by histology.

\section{Enzyme linked immunosorbent assay}

ELISA assays were performed with a commercial TGF$\beta 1$ ELISA kit (R\&D Systems, Minneapolis, MN). Conditioned medium was collected from wells, aliquoted, and stored frozen. Assays were performed in duplicate, and readings were compared with standard curves obtained with standard protein provided with the kit. Means and standard deviations of concentrations in triplicate samples were compared by $t$-test.

\section{Western blot analysis}

Extraction of total soluble proteins from cultivated cells and western-blot analysis were performed as previously described [20]. Primary antibodies used in western blot analysis were specific for either TGF- $\beta$ (Abcam, Hongkong, China, Cat.ab66043) or $\beta$-actin (Invitrogen, Cat. AM4302). Horseradish peroxidase conjugated goat anti-rabbit IgG was used as the secondary antibody (R\&D systerms, Cat. BAF008).

\section{Short interfering RNA (siRNA) synthesis and transient transfection}

Three siRNA sequences of TGF- $\beta 1$ were designed using Oligoengine software and verified by nucleotide BLAST searches. Three candidate sequences and a control sequence with no significant homology were listed in Table 1 . Cells $\left(1-3 \times 10^{6}\right)$ growing to $50 \%-60 \%$ confluence in $10 \mathrm{~cm}$ petri dishes were transfected with siRNA sequences or their corresponding mock sequences using a Lipofectamine 2000 kit (Invitrogen, Cat.11668-019) with the procedure provided by the manufacturer. Cells were observed under a fluorescence microscope and harvested $48 \mathrm{~h}$ after transfection.

\section{Statistical analysis}

All data, expressed as mean \pm SEM, were from at least three separate experiments. Data sets were analyzed by

Table 1 Sequence of the oligonucleotides for siRNA construct-making assays

\begin{tabular}{cccl}
\hline Assays & Gene & & Sequence $\left(\mathbf{5}^{\prime} \rightarrow \mathbf{3}^{\prime}\right)$ \\
\hline & Sequence 1 & Sense & CACUGCAAGUGGACAUCAATT \\
& & Antisense & UUGAUGUCCACUUGCAGUGTT \\
& Sequence 2 & Sense & GCAAGACUAUCGACAUGGATT \\
TGFß1 siRNA & Antisense & UCCAUGUCGAUAGUCUUGCTT \\
& Sequence 3 & Sense & GCAUAUAUAUGUUCUUCATT \\
& & Antisense & UUGAAGAACAUAUAUAUGCTT \\
& Control & Sense & UUCUCCGACGUGUCACGUTT \\
& & Antisense & ACGUGACACGUUCGGAGATT \\
& &
\end{tabular}




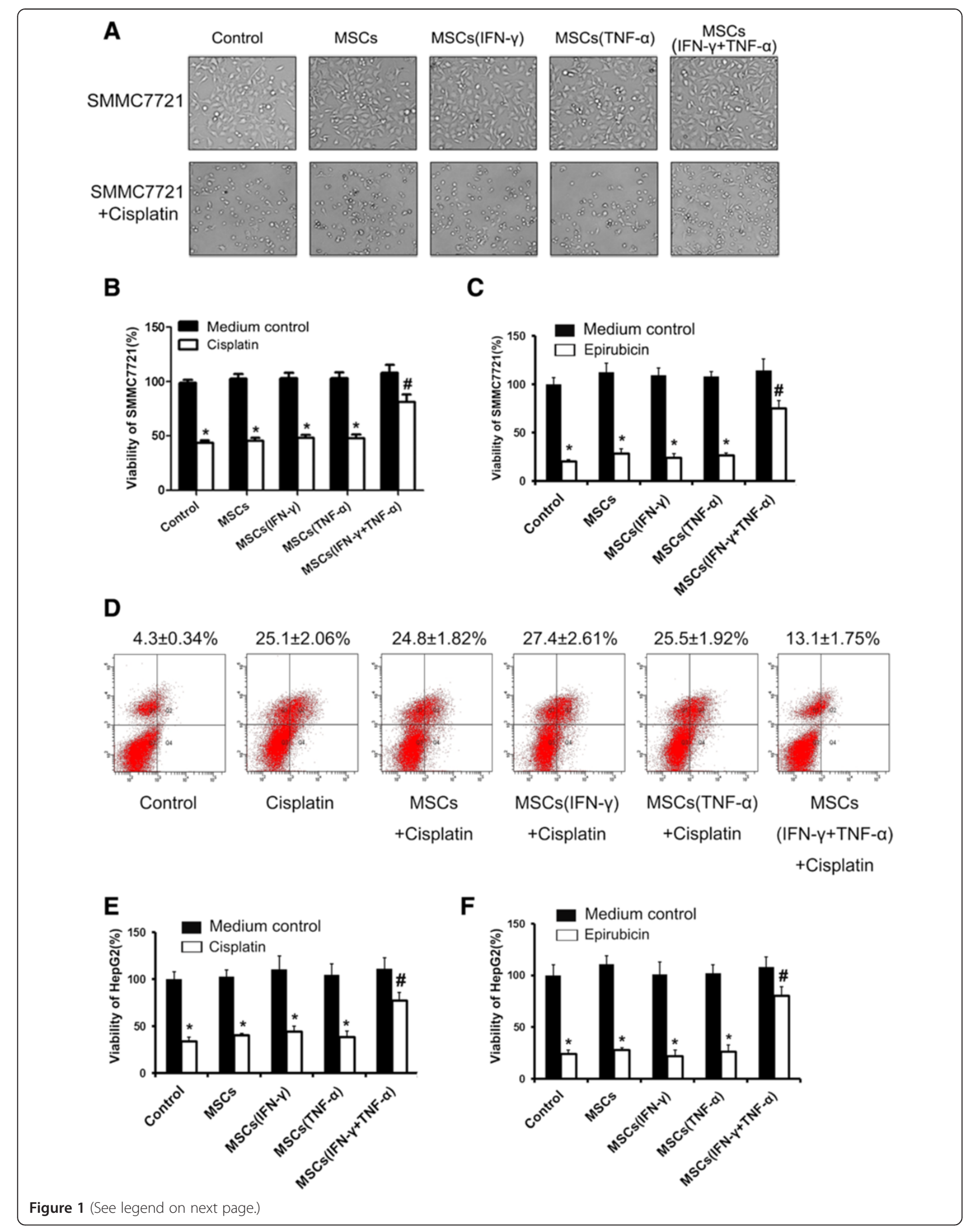


(See figure on previous page.)

Figure 1 Conditioned medium from the culture of inflammatory cytokine-stimulated MSCs enhanced chemoresistance of HCC cells in vitro. (A) SMMC-7721 cells were treated with cisplatin $(20 \mu \mathrm{M})$ with conditioned medium collected from MSCs which were pretreated with inflammatory cytokines or not. The morphology of the cells was captured by microscope. MTT was employed to examine the proliferation of SMMC-7721 cells, which were treated with cisplatin $(20 \mu \mathrm{M}) \mathbf{( B )}$ or epirubicin $(0.55 \mu \mathrm{g} / \mathrm{ml}) \mathbf{( C )}$ with conditioned medium collected from MSCs which were pretreated with inflammatory cytokines or not. (D) SMMC-7721 cells were cultured in a 6-well plate with an existence of cisplatin $(20 \mu \mathrm{M})$ and the conditioned medium collected from MSCs which were pretreated with inflammatory cytokines or not were added in SMMC-7721 culture medium for 24 hours. PI/Annexin V-FITC assay was used to measure apoptotic SMMC-7721 cells by flow cytometry. MTT was employed to examine the proliferation of HepG2 cells, which were treated with cisplatin $(20 \mu \mathrm{M})(\mathbf{E})$ or epirubicin $(0.55 \mu \mathrm{g} / \mathrm{ml}) \mathbf{( F )}$ with conditioned medium collected from MSCs which were pretreated with inflammatory cytokines or not. ( ${ }^{*} \mathrm{Compared}$ with the group that untreated with chemotherapy drugs $\mathrm{P}<0.05$; \#Compared with the group that treated with the conditioned medium collected from MSCs which were pretreated with inflammatory cytokines or not $P<0.05)$.

analysis of variance (ANOVA) with a posteriori contrast by least significant difference (for comparisons among multiple groups) or by Student $t$-test (for comparison between two groups) using the Microsoft Excel Analysis Tool Pak (Microsoft, Redmond, WA). P $<0.05$ was considered to be statistically significant.

\section{Results}

Inflammatory cytokine-stimulated MSCs enhanced chemoresistance of hepatocellular carcinoma cells

To study the effect of MSCs on the development of chemoresistance in HCC cells in inflammatory environment, we determined influence of chemotherapeutic agent cisplatin on morphological changes of HCC cell line-SMMC7721 cells in the presence of different types of conditioned media from cultures of MSCs. The results showed that cisplatin effectively inhibited the growth of SMMC7721 cells. This cisplatin-induced inhibition of SMMC7721 cell growth was attenuated when cells were cultured with conditioned medium from the culture of MSCs that were pre-stimulated with a combination of IFN- $\gamma$ and TNF- $\alpha$. The development of chemoresistance was not observed in SMMC7721 cells when they were cultured with conditioned medium from the culture of untreated MSCs or from the culture of MSCs pretreated with either IFN- $\gamma$ or TNF- $\alpha$ alone (Figure 1A). SMMC7721 cell proliferation was also determined by MTT assay to verify the development of chemoresistance in these cells. The results confirmed that conditioned medium from the culture of MSCs pre-stimulated with the combination of IFN- $\gamma$ and TNF- $\alpha$ could effectively improve SMMC7721 cell proliferation in the presence of the chemotherapeutic agent. In contrast, SMMC7721 cell proliferation was significantly inhibited by cisplatin or epirubicin in control groups (Figure $1 \mathrm{~B}$ and $\mathrm{C}$ ). Cisplatin treatment effectively enhanced apoptosis in SMMC7721 cells (Figure 1D). Conditioned medium of MSCs prestimulated with the combination of IFN- $\gamma$ and TNF- $\alpha$ caused a significant reduction of cisplatin-induced apoptosis in cultured SMMC7721 cells. We also employed the culture model of HepG2 cells to study chemoresistance induced by MSCs. The results demonstrated that conditioned medium of MSCs pre-stimulated with the combination of IFN- $\gamma$ and TNF- $\alpha$ could effectively protect HepG2 cells from cell toxicity caused by cisplatin or epirubicin (Figure 1E-F). We further examined the MSCs-induced chemoresistance in HCC cells in the nude mouse model. The results showed that MSCs pretreated with the combination of IFN- $\gamma$ and TNF- $\alpha$ could lead to resistance to chemotherapy in HCC cells in vivo (Figure 2A and B).

\section{Inflammatory cytokine-stimulated MSCs induced autoph- agy in hepatocellular carcinoma cells}

In previous studies, we have demonstrated that autophagy contributes to the resistance of HCC cells to chemotherapeutic agents [21]. We hypothesized that MSCs might induce autophagy of HCC cells in inflammatory environment. Analysis of autophagy in SMMC7721 cells was performed using an expression vector encoding GFP-LC3 which is concentrated in autophagic vacuoles, resulting in punctate fluorescence within cells undergoing autophagy. As shown in Figure $3 \mathrm{~A}$ and B, MSCs pretreated with the combination of IFN- $\gamma$ and TNF- $\alpha$ effectively induced autophagy in SMMC7721 cells, which exhibited a significantly high number of punctate GFP. In contrast, SMMC7721 cells in control groups showed primarily diffused fluorescence. In order to confirm the above observation, we employed transmission electron microscopy to detect the autophagy in SMMC7721 cells. The results demonstrated that the occurrence of autophagy could be observed in SMMC7721 cells when cultured with conditioned medium from the culture of MSCs pre-stimulated with the combination of IFN- $\gamma$ and TNF- $\alpha$ (Figure $3 \mathrm{C}$ ).

\section{Inhibition of autophagy restored the sensitivity of HCC cells to chemotherapy}

In order to further verify that occurrence of autophagy in HCC cells lead to enhancement of chemoresistance in HCC cells, we examined the recurrence of HCC cell sensitivity to chemotherapy in the presence of autophagy inhibitors. The results showed that the autophagy inhibitor CQ and 3-MA could effectively restore the sensitivity of HCC cells to chemotherapeutic agents. Addition of autophagy inhibitors to the cell culture 

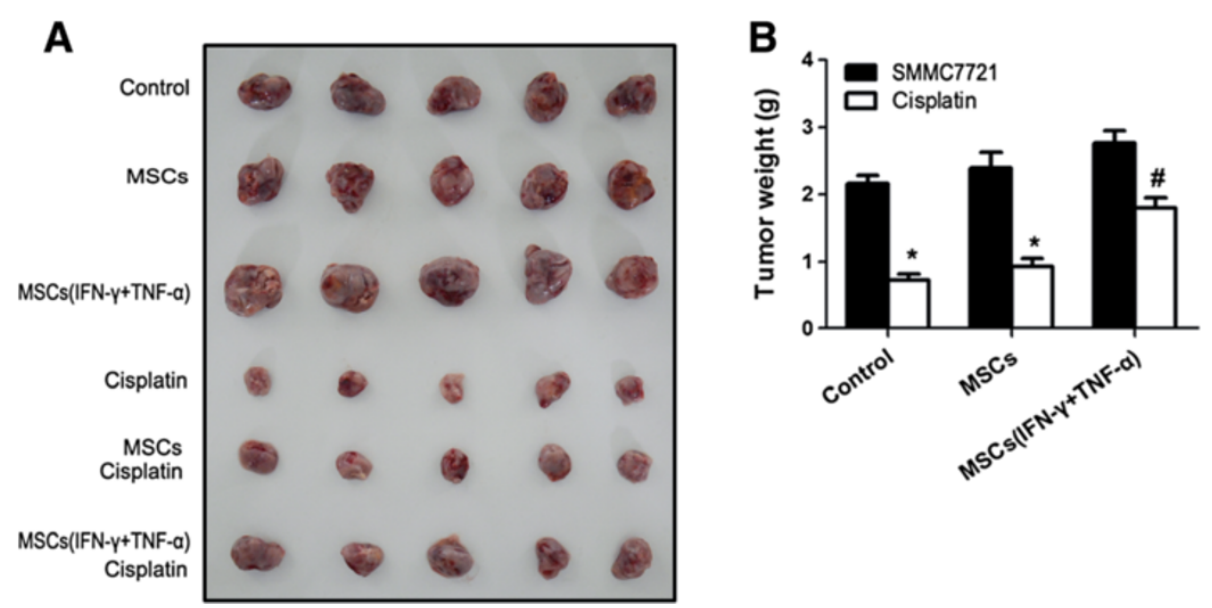

Figure 2 Inflammatory cytokine-stimulated MSCs enhanced chemoresistance of HCC cells in vivo. (A) MSCS $\left(1 \times 10^{6}\right)$ were pretreated with inflammatory cytokines IFN- $\gamma$ and TNF-a $\left(20 \mathrm{ng} / \mathrm{ml}\right.$ each) for 12 hours and then mixed with SMMC-7721 cells $\left(5 \times 10^{6}\right)$ to perform subcutaneous administration in the nude mice armpit area (five mice for each group). When tumors reached a mean tumor volume of $150 \mathrm{~mm}^{3}$, recipients were injected in tumor in situ with cisplatin ( $4 \mathrm{mg} / \mathrm{kg}$ ) every 3 days. After 27 days of implantation, the animals were sacrificed and tumors were dissected. (B) The weight of tumor were measured after been removed from the mice. ${ }^{*}$ Compared with the group that untreated with chemotherapy drugs $\mathrm{P}<0.05$; \#Compared with the group that MSCs were pretreated with inflammatory cytokines or not $\mathrm{P}<0.05$ ).

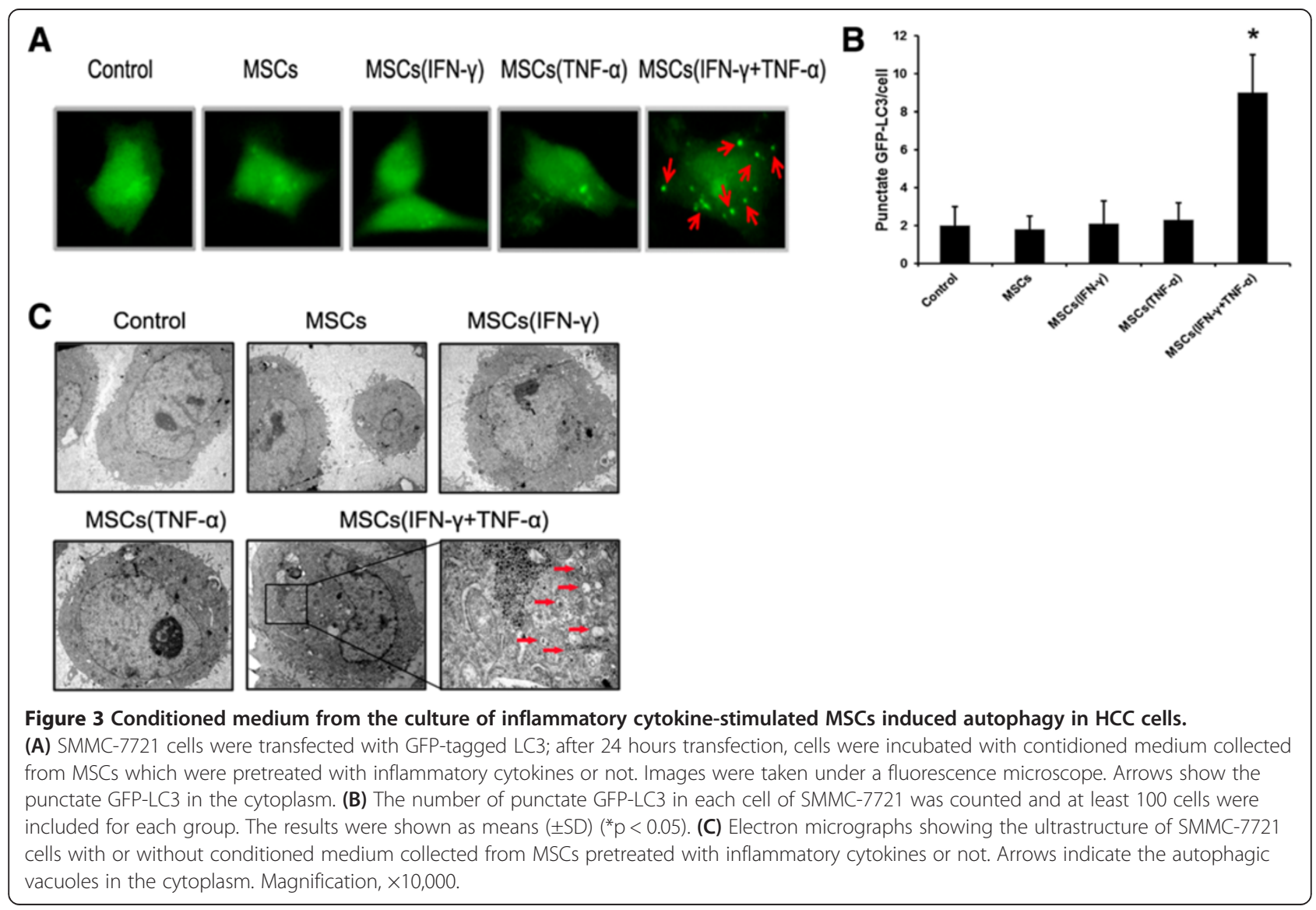


resulted in inhibition of proliferation and increase in apoptosis in HCC cells following treatment with chemotherapeutic agents (Figure 4A-D).

\section{Inflammatory cytokines induced overexpression of TGF- $\beta$ by MSCs}

Several studies have suggested that TGF- $\beta$ plays an important role in induction of autophagy [22-24]. Therefore, we examined TGF- $\beta$ expression by MSCs in response to IFN- $\gamma$ and TNF- $\alpha$ stimulation. As shown in Figure 5, stimulation with the combination of IFN- $\gamma$ and TNF- $\alpha$ caused a significant up-regulation of TGF- $\beta$ expression at both mRNA and protein levels in MSCs.

Inhibition of TGF- $\beta$ expression by MSCs diminished the ability of MSCs to induce autophagy and chemoresistance in HCC cells

In order to define the role of TGF- $\beta$ in MSC-mediated occurrence of autophagy and development of chemoresistance in HCC cells, TGF- $\beta$ expression by MSCs in response to IFN- $\gamma$ plus TNF- $\alpha$ stimulation was knockdown by transfecting MSCs with siRNA against TGF- $\beta$
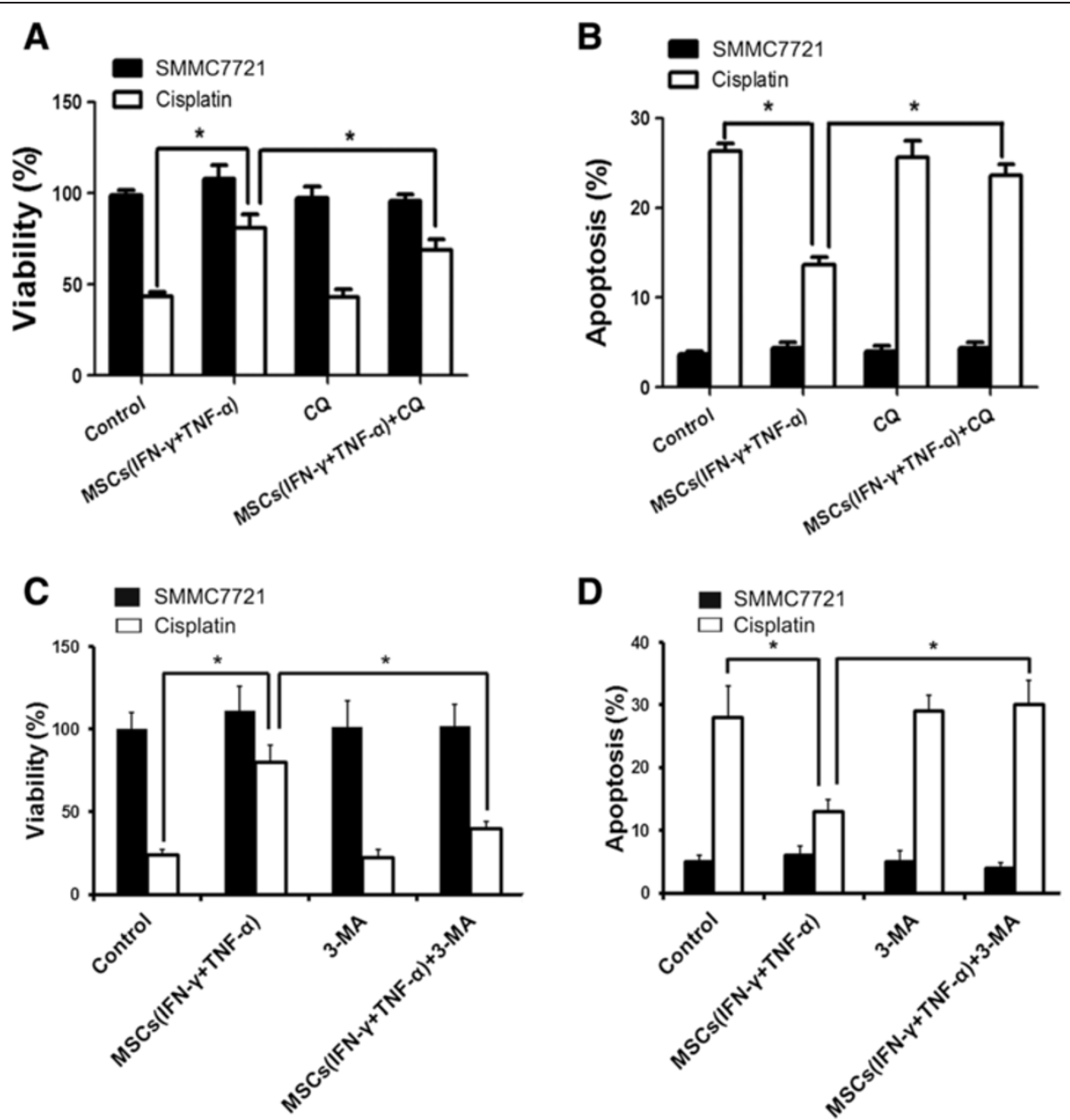

Figure 4 Inhibition of autophagy restored HCC cell sensitivity to chemotherapy. (A) SMMC-7721 cells $\left(1 \times 10^{4} /\right.$ well) were cultured in a 96-well plate with an existence of cisplatin $(20 \mu \mathrm{M})$ and the conditioned medium collected from MSCs which were pretreated with inflammatory cytokines or not were added in SMMC-7721 culture medium for 24 hours. The occurrence of autophagy was inhibited by autophagy inhibitor-CQ $(10 \mu M)$. MTT was employed to examine the proliferation of SMMC-7721 cells. (B) SMMC-7721 cells were cultured in a 6-well plate with an existence of cisplatin $(20 \mu \mathrm{M})$ and the conditioned medium collected from MSCs which were pretreated with inflammatory cytokines or not were added in SMMC-7721 culture medium for 24 hours. The occurrence of autophagy was inhibited by autophagy inhibitor-CQ (10 $\mu \mathrm{M})$. PI/Annexin V-FITC assay was used to measure apoptotic SMMC-7721 cells ells by flow cytometry. (C) SMMC-7721 cells $\left(1 \times 10^{4} /\right.$ well) were cultured in a 96-well plate with an existence of cisplatin $(20 \mu \mathrm{M})$ and the conditioned medium collected from MSCs which were pretreated with inflammatory cytokines or not were added in SMMC-7721 culture medium for 24 hours. The occurrence of autophagy was inhibited by autophagy inhibitor-3MA (2 mM). MTT was employed to examine the proliferation of SMMC-7721 cells. (D) SMMC-7721 cells were cultured in a 6-well plate with an existence of cisplatin $(20 \mu \mathrm{M})$ and the conditioned medium collected from MSCs which were pretreated with inflammatory cytokines or not were added in SMMC-7721 culture medium for 24 hours. The occurrence of autophagy was inhibited by autophagy inhibitor-3-MA (2 mM). PI/Annexin V-FITC assay was used to measure apoptotic SMMC-7721 cells ells by flow cytometry. ( $\left.{ }^{*} \mathrm{P}<0.05\right)$. 


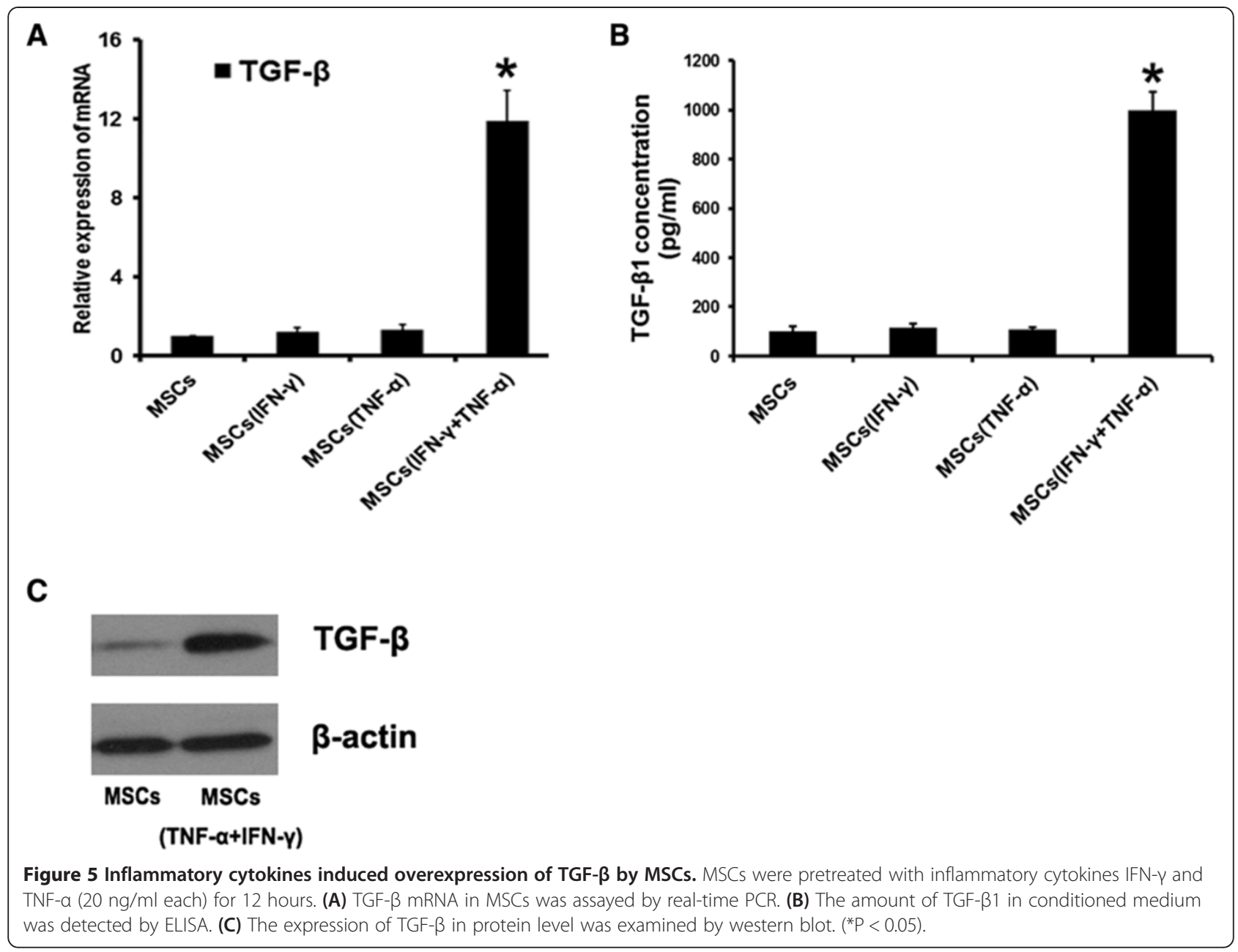

mRNA. Conditioned medium from the culture of TGF- $\beta$ knockdown MSCs failed to induce formation of autophagy in HCC cells (Figure 6A and B). Furthermore, blockade of TGF- $\beta$ expression by MSCs diminished the ability of these MSCs to induce chemoresistance in HCC cells (Figure 6C and D). These results indicate that up-regulation of TGF$\beta$ expression by MSCs in inflammatory microenvironment plays a key role in inducing autophagy and development of chemoresistance in HCC cells.

\section{Discussion}

Autophagy is a survival mechanism for both prokaryotic and eukaryotic cells in the nutrient deficient environment [25-27]. Energy, amino acids, and other precursor molecules for maintaining cellular homeostasis and facilitating cell survival are produced through this process [28-30]. It has been reported that autophagy associates with various physiological and pathological processes, including differentiation, tumorigenesis, chemoresistance and adaptation to changed environmental conditions [31]. The process of autophagy includes three steps: (1) autophagosome formation, (2) lysosomal fusion with the autophagosome, and (3) lysosomal degradation to produce precursor molecules, such as amino acids and fatty acids, to be reutilized for de novo synthesis of macromolecules and generation of energy [32]. Autophagy is activated by hypoxia, starvation and TGF- $\beta 1[21,33,34]$. On the other hand, the occurrence of autophagy can be inhibited not only by the key factor in autophagy associated signal pathway such as Atg 7 and Beclin 1 but also by autophagy inhibitor CQ and 3-MA. 3-MA serves as an inhibitor of phosphatidylinositol 3-kinase, which blocks autophagosome formation to inhibit autophagy [35]. CQ is a lysosomotropic drug that impairs autophagic protein degradation. CQ blocks the last step of the autophagy pathway, which leads to the accumulation of autophagosomes [36,37].

MSCs play an important role in the pathogenesis of various degenerative diseases and immune disorders. This cell population is a potential target for correcting aberrant immune reactions. Studies have shown that MSCs can be induced and expanded ex vivo. These precursor cells can terminally differentiate into osteoblasts, chondrocytes, adipocytes, myotubes, neural cells and 

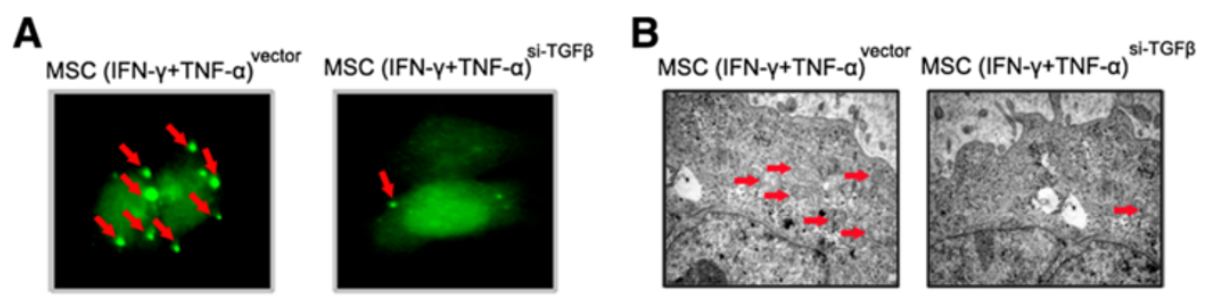

C

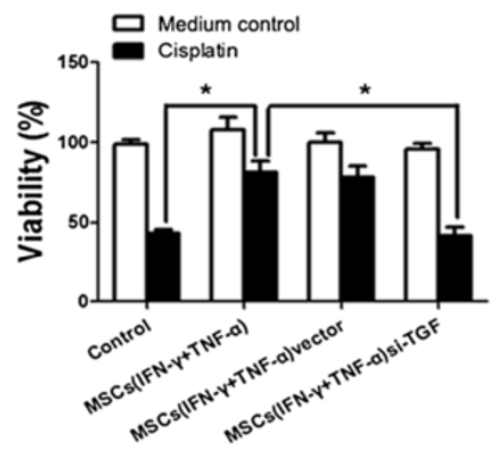

D

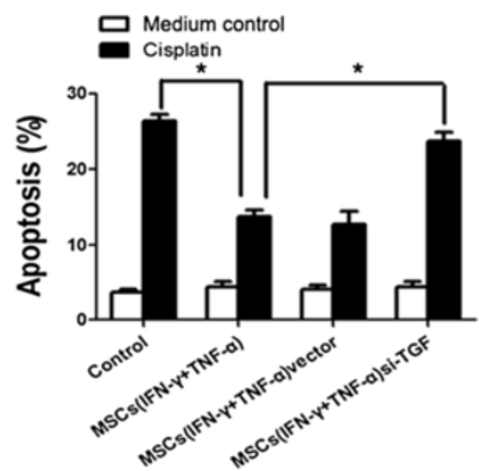

Figure 6 Inhibition of TGF- $\beta$ expression by MSCs diminished the ability of MSCs in inducing autophagy and chemoresistance in HCC cells. (A) MSCs were transfected with si-TGF $\beta$ and then been stimulated by both IFN- $\gamma$ and TNF-a for 12 hours. The conditioned medium was collected for further investigation. SMMC-7721 cells were transfected with GFP-tagged LC3; after 24 hours transfection, cells were incubated with contidioned medium collected from MSCs ${ }^{\text {Si-TGF }}$. Images were taken under a fluorescence microscope. Arrows show the punctate GFP-LC3 in the cytoplasm. (B) Electron micrographs showing the ultrastructure of SMMC-7721 cells with or without conditioned medium collected from MSCS pretreated with inflammatory cytokines or not. Arrows indicate the autophagic vacuoles in the cytoplasm. Magnification, $\times 10000$. (C) SMMC-7721 cells $\left(1 \times 10^{4} /\right.$ well) were cultured in a 96-well plate with an existence of cisplatin $(20 \mu \mathrm{M})$ and the conditioned medium collected from MSC ${ }^{\text {si-TGF } \beta}$ was added in SMMC-7721 culture medium for 24 hours. MTT was employed to examine the proliferation of SMMC-7721 cells. (D) SMMC-7721 cells were cultured in a 6-well plate with an existence of cisplatin $(10 \mu \mathrm{g} / \mathrm{mL})$ and the conditioned medium collected from MSC $s^{\text {si-TGF } \beta}$ was added in SMMC-7721 culture medium for 24 hours. PI/Annexin V-FITC assay was used to measure apoptotic SMMC-7721 cells by flow cytometry. ( $\left.{ }^{*} \mathrm{P}<0.05\right)$.

hematopoietic supporting stroma $[9,10,38]$. In previous studies, we have demonstrated that in tumor inflammatory microenvironment, MSCs may exert immunosuppressive function through iNOS to protect tumor cell from immune surveillance [39]. Furthermore, MSCs have been shown to promote tumor growth by enhancing tumor angiogenesis via HIF-1 $\alpha$-VEGF signalling pathway in the colon cancer model [40]. In this study, we observed that in inflammatory microenvironment, MSCs could effectively induce chemoresistance in HCC cell line cells.

In previous studies, we have demonstrated that autophagy decreases the sensitivity of hepatoma cells to chemotherapeutic agents by affecting their apoptotic potential [21]. In addition, we have shown that autophagy activated by hypoxia mediates the tolerance of hepatocellular carcinoma cells to nutrient deprivation, which is dependent on the activity of Beclin 1 [41]. In this study, we found that MSC-induced chemoresistance in HCC cell line cells was associated with the occurrence of autophagy, a protective mechanism of $\mathrm{HCC}$ cells to resist chemotherapeutic agents. Stimulation with the combination of IFN- $\gamma$ and TNF- $\alpha$ could provoke TGF- $\beta$ expression by MSCs. The enhancement of chemoresistance in HCC cell line cells was in a TGF- $\beta$ dependent manner. Our results suggest that overexpression of TGF- $\beta$ by MSCs in the HCC inflammatory microenviroment may favor the development of chemoresistance in HCC cells by inducing autophagy.

TGF- $\beta$ plays an important role in regulating cell growth, differentiation and migration. TGF- $\beta$ has been reported to induce autophagy in normal bovine mammary epithelial BME-UV1 cells [12]. Furthermore, TGF- $\beta$ also induced autophagy not only in some mammary carcinoma cells but also in human hepatocellular carcinoma cells. Accumulation of autophagosomes and conversion of LC3 from type 1 to type 2 induced by TGF- $\beta$ results in degradation of long-lived proteins. TGF- $\beta$ upregulates the expression of ATG5, ATG7, BECLIN1, and death-associated protein kinase (DAPK) in mRNA level [6]. Recently, Roodhart and colleagues have reported that endogenous MSCs become activated during treatment with platinum analogs and secrete factors which protect tumor cells against a range of chemotherapeutic agents [42]. Our results reveal another important fact that tumor inflammatory microenvironment is a key player in activating MSCs to induce chemoresistance of HCC cells. Inflammation is a fundamental 
feature during the development of hepatocellular carcinoma, which exists not only within the tumor tissue but also in tissues surrounding the tumor. MSCs in inflammatory microenvironment may persistently promote the development of chemoresistance in HCC cells during tumor growth. One mechanism underlying MSC-promoted development of chemoresistance in $\mathrm{HCC}$ cells is via their overexpression of TGF- $\beta$ in response to inflammatory stimuli in the tumor microenvironment. Inhibition of MSC activation in the inflammatory microenvironment may serves as a potential approach to improve chemosensitivity of HCC cells.

\section{Conclusions}

Taken together, these results suggest that increase in TGF- $\beta$ expression by MSCs in the inflammatory microenvironment of HCC promotes the development of chemoresistance in HCC cells.

\section{Abbreviations}

MSCs: Mesenchymal stem cells; HCC: Hepatocellular carcinoma;

TGF- $\beta$ : Transforming growth factor $\beta$.

\section{Competing interests}

The authors declare that they have no conflicts of interests.

\section{Authors' contributions}

ZPH: Conception and design, data analysis and interpretation, manuscript writing. YYJ: Conception and design, collection and/or assembly of data, manuscript writing. YX: Collection and/or assembly of data, data analysis and interpretation. SSZ: Conception and design, data analysis and interpretation. JH: Administrative support, collection and/or assembly of data. YM: Provision of study material or patients, collection and/or assembly of data, data analysis and interpretation. FHY: Provision of study material or patients, collection and/or assembly of data. XQL: Collection and/or assembly of data, data analysis and interpretation. MCW: Data analysis and interpretation. PZ: Conception and design, data analysis and interpretation. LXW: Conception and design, financial support, data analysis and interpretation, final approval of manuscript. All authors read and approved the final manuscript.

\section{Acknowledgements}

This project was supported by the Key Basic Research Project of China (Grant NO. 2012CBA01303, 2011CB966200, 2010CB945600, 2011CB965100); Key project of National Natural Science Foundation of China(Grant NO. 81030041): National Natural Science Foundation of China (Grant NO 31171321, 81101622, 81372330); Special Funds for National key Sci-Tech Sepcial Project of China (Grant NO. 2012ZX10002-016, 2012ZX10002011-011); Shanghai Science and Technology Committee (Grant NO. 11ZR1449500, 12ZR1439800); Shanghai Municipal Health Bureau(Grant NO. XYQ2011044) and Science Fund for Creative Research Groups, NSFC, China (Grant NO. 81221061)

\footnotetext{
Author details

${ }^{1}$ Tumor Immunology and Gene Therapy Center, Eastern Hepatobiliary Surgery Hospital, the Second Military Medicial University, 225 Changhai Road, Shanghai 200438, China. ${ }^{2}$ Department of Comprehensive Treatment, Eastern Hepatobiliary Surgery Hospital, the Second Military Medicial University, Shanghai, China. ${ }^{3}$ Department of Radiation Oncology, Eastern Hepatobiliary Surgery Hospital, the Second Military Medical University, Shanghai, China. ${ }^{4}$ Department of Gastroenterology, Eastern Hepatobiliary Surgery Hospital, the Second Military Medical University, Shanghai, China. ${ }^{5}$ Department of Ophthalmology, Shanghai Tenth People's Hospital and Tongji Eye Institute, Tongji University School of Medicine, Shanghai, China. ${ }^{6}$ Department of Surgery, College of Human Medicine, Michigan State University, East Lansing, $\mathrm{MI}$, USA.
}

Received: 10 September 2013 Accepted: 15 February 2014 Published: 28 April 2014

\section{References}

1. Meads MB, Gatenby RA, Dalton WS: Environment-mediated drug resistance: a major contributor to minimal residual disease. Nat Rev Cancer 2009, 9(9):665-674.

2. Shekhar MP, Santner S, Carolin KA, Tait L: Direct involvement of breast tumor fibroblasts in the modulation of tamoxifen sensitivity. Am J Pathol 2007, 170(5):1546-1560.

3. Muerkoster S, Wegehenkel K, Arlt A, Witt M, Sipos B, Kruse ML, Sebens T, Kloppel G, Kalthoff H, Folsch UR, Schafer H: Tumor stroma interactions induce chemoresistance in pancreatic ductal carcinoma cells involving increased secretion and paracrine effects of nitric oxide and interleukin1beta. Cancer Res 2004, 64(4):1331-1337.

4. Hazlehurst LA, Landowski TH, Dalton WS: Role of the tumor microenvironment in mediating de novo resistance to drugs and physiological mediators of cell death. Oncogene 2003, 22(47):7396-7402.

5. Weaver VM, Lelievre S, Lakins JN, Chrenek MA, Jones JC, Giancotti F, Werb Z, Bissell MJ: Beta4 integrin-dependent formation of polarized threedimensional architecture confers resistance to apoptosis in normal and malignant mammary epithelium. Cancer Cell 2002, 2(3):205-216.

6. Kiyono K, Suzuki HI, Matsuyama H, Morishita Y, Komuro A, Kano MR, Sugimoto K, Miyazono K: Autophagy is activated by TGF-beta and potentiates TGF-beta-mediated growth inhibition in human hepatocellular carcinoma cells. Cancer Res 2009, 69(23):8844-8852.

7. Lazarus HM, Koc ON, Devine SM, Curtin P, Maziarz RT, Holland HK, Shpall EJ, McCarthy P, Atkinson K, Cooper BW, Gerson SL, Laughlin MJ, Loberiza FR Jr, Moseley AB, Bacigalupo A: Cotransplantation of HLA-identical sibling culture-expanded mesenchymal stem cells and hematopoietic stem cells in hematologic malignancy patients. Biol Blood Marrow Transplant 2005, 11(5):389-398

8. da Silva ML, Chagastelles PC, Nardi NB: Mesenchymal stem cells reside in virtually all post-natal organs and tissues. J Cell Sci 2006, 119(Pt 11):2204-2213.

9. Barry FP, Murphy JM: Mesenchymal stem cells: clinical applications and biological characterization. Int J Biochem Cell Biol 2004, 36(4):568-584.

10. Pittenger MF, Mackay AM, Beck SC, Jaiswal RK, Douglas R, Mosca JD, Moorman MA, Simonetti DW, Craig S, Marshak DR: Multilineage potential of adult human mesenchymal stem cells. Science 1999, 284(5411):143-147.

11. Noel D, Djouad F, Jorgense C: Regenerative medicine through mesenchymal stem cells for bone and cartilage repair. Curr Opin Investig Drugs 2002, 3(7):1000-1004

12. Gajewska M, Gajkowska B, Motyl T: Apoptosis and autophagy induced by TGF-B1 in bovine mammary epithelial BME-UV1 cells. J Physiol Pharmacol 2005, 56(Suppl 3):143-157.

13. Loebinger MR, Kyrtatos PG, Turmaine M, Price AN, Pankhurst Q, Lythgoe MF, Janes SM: Magnetic resonance imaging of mesenchymal stem cells homing to pulmonary metastases using biocompatible magnetic nanoparticles. Cancer Res 2009, 69(23):8862-8867.

14. Kidd S, Spaeth E, Dembinski JL, Dietrich M, Watson K, Klopp A, Battula VL, Weil M, Andreeff M, Marini FC: Direct evidence of mesenchymal stem cell tropism for tumor and wounding microenvironments using in vivo bioluminescent imaging. Stem Cells 2009, 27(10):2614-2623.

15. Ringe J, Strassburg S, Neumann K, Endres M, Notter M, Burmester GR, Kaps C, Sittinger M: Towards in situ tissue repair: human mesenchymal stem cells express chemokine receptors CXCR1, CXCR2 and CCR2, and migrate upon stimulation with CXCL8 but not CCL2. J Cell Biochem 2007, 101(1):135-146.

16. Mantovani A, Allavena P, Sica A, Balkwill F: Cancer-related inflammation. Nature 2008, 454(7203):436-444.

17. Nasef A, Chapel A, Mazurier C, Bouchet S, Lopez M, Mathieu N, Sensebe L, Zhang Y, Gorin NC, Thierry D, Fouillard L: Identification of IL-10 and TGFbeta transcripts involved in the inhibition of T-lymphocyte proliferation during cell contact with human mesenchymal stem cells. Gene Expr 2007, 13(4-5):217-226

18. Di Nicola M, Carlo-Stella C, Magni M, Milanesi M, Longoni PD, Matteucci P, Grisanti S, Gianni AM: Human bone marrow stromal cells suppress T-lymphocyte proliferation induced by cellular or nonspecific mitogenic stimuli. Blood 2002, 99(10):3838-3843. 
19. Coffelt SB, Marini FC, Watson K, Zwezdaryk KJ, Dembinski JL, LaMarca HL, Tomchuck SL, Honer Zu Bentrup K, Danka ES, Henkle SL, Scandurro AB: The pro-inflammatory peptide LL-37 promotes ovarian tumor progression through recruitment of multipotent mesenchymal stromal cells. Proc Natl Acad Sci USA 2009, 106(10):3806-3811.

20. Sun T, Zhao N, Zhao XL, Gu Q, Zhang SW, Che N, Wang XH, Du J, Liu YX, Sun BC Expression and functional significance of Twist1 in hepatocellular carcinoma: its role in vasculogenic mimicry. Hepatology 2010, 51(2):545-556.

21. Song J, Qu Z, Guo X, Zhao Q, Zhao X, Gao L, Sun K, Shen F, Wu M, Wei L: Hypoxia-induced autophagy contributes to the chemoresistance of hepatocellular carcinoma cells. Autophagy 2009, 5(8):1131-1144.

22. Ding Y, Kim JK, Kim SI, Na HJ, Jun SY, Lee SJ, Choi ME: TGF-\{beta\}1 protects against mesangial cell apoptosis via induction of autophagy. $J$ Biol Chem 2010, 285(48):37909-37919.

23. Koesters R, Kaissling B, Lehir M, Picard N, Theilig F, Gebhardt R, Glick AB, Hahnel B, Hosser H, Grone HJ, Kriz W: Tubular overexpression of transforming growth factor-beta1 induces autophagy and fibrosis but not mesenchymal transition of renal epithelial cells. Am J Pathol 2010, 177(2):632-643.

24. Suzuki HI, Kiyono K, Miyazono K: Regulation of autophagy by transforming growth factor-beta (TGF-beta) signaling. Autophagy 2010, 6(5):645-647.

25. Tang H, Da L, Mao Y, Li Y, Li D, Xu Z, Li F, Wang Y, Tiollais P, Li T, Zhao M: Hepatitis $B$ virus $X$ protein sensitizes cells to starvation-induced autophagy via up-regulation of beclin 1 expression. Hepatology 2009, 49(1):60-71.

26. Klionsky DJ, Ohsumi Y: Vacuolar import of proteins and organelles from the cytoplasm. Annu Rev Cell Dev Biol 1999, 15:1-32.

27. Mizushima N, Noda T, Yoshimori T, Tanaka Y, Ishii T, George MD, Klionsky DJ, Ohsumi M, Ohsumi Y: A protein conjugation system essential for autophagy. Nature 1998, 395(6700):395-398.

28. Levine B, Klionsky DJ: Development by self-digestion: molecular mechanisms and biological functions of autophagy. Dev Cell 2004, 6(4):463-477.

29. Kim J, Klionsky DJ: Autophagy, cytoplasm-to-vacuole targeting pathway, and pexophagy in yeast and mammalian cells. Annu Rev Biochem 2000, 69:303-342.

30. Klionsky DJ, Emr SD: Autophagy as a regulated pathway of cellular degradation. Science 2000, 290(5497):1717-1721.

31. Carew JS, Medina EC, Esquivel JA 2nd, Mahalingam D, Swords R, Kelly K, Zhang $H$, Huang P, Mita AC, Mita MM, Giles FJ, Nawrocki ST: Autophagy inhibition enhances vorinostat-induced apoptosis via ubiquitinated protein accumulation. J Cell Mol Med 2010, 14(10):2448-2459.

32. Shintani T, Klionsky DJ: Autophagy in health and disease: a double-edged sword. Science 2004, 306(5698):990-995.

33. Hou J, Han ZP, Jing YY, Yang X, Zhang SS, Sun K, Hao C, Meng Y, Yu FH, Liu $X Q$, Shi YF, Wu MC, Zhang L, Wei LX: Autophagy prevents irradiation injury and maintains stemness through decreasing ROS generation in mesenchymal stem cells. Cell Death Dis 2013, 4:e844.

34. Kim G, Jun JB, Elkon KB: Necessary role of phosphatidylinositol 3-kinase in transforming growth factor beta-mediated activation of Akt in normal and rheumatoid arthritis synovial fibroblasts. Arthritis Rheum 2002, 46(6):1504-1511.

35. Takatsuka C, Inoue Y, Matsuoka K, Moriyasu Y: 3-methyladenine inhibits autophagy in tobacco culture cells under sucrose starvation conditions. Plant Cell Physiol 2004, 45(3):265-274.

36. Lum JJ, Bauer DE, Kong M, Harris MH, Li C, Lindsten T, Thompson CB: Growth factor regulation of autophagy and cell survival in the absence of apoptosis. Cell 2005, 120(2):237-248.

37. Glaumann H, Ahlberg J: Comparison of different autophagic vacuoles with regard to ultrastructure, enzymatic composition, and degradation capacity-formation of crinosomes. Exp Mol Pathol 1987, 47(3):346-362.

38. Xu W, Zhang X, Qian H, Zhu W, Sun X, Hu J, Zhou H, Chen Y: Mesenchymal stem cells from adult human bone marrow differentiate into a cardiomyocyte phenotype in vitro. Exp Biol Med (Maywood) 2004, 229(7):623-631.

39. Han Z, Tian Z, Lv G, Zhang L, Jiang G, Sun K, Wang C, Bu X, Li R, Shi Y, Wu $M$, Wei L: Immunosuppressive effect of bone marrow-derived mesenchymal stem cells in inflammatory microenvironment favours the growth of B16 melanoma cells. J Cell Mol Med 2011, 15(11):2343-2352.

40. Liu Y, Han ZP, Zhang SS, Jing YY, Bu XX, Wang CY, Sun K, Jiang GC, Zhao X, Li R, Gao L, Zhao QD, Wu MC, Wei LX: Effects of inflammatory factors on mesenchymal stem cells and their role in the promotion of tumor angiogenesis in colon cancer. J Bio/ Chem 2011, 286(28):25007-25015.
41. Song J, Guo X, Xie X, Zhao X, Li D, Deng W, Song Y, Shen F, Wu M, Wei L: Autophagy in hypoxia protects cancer cells against apoptosis induced by nutrient deprivation through a Beclin1-dependent way in hepatocellular carcinoma. J Cell Biochem 2011, 112(11):3406-3420.

42. Roodhart JM, Daenen LG, Stigter EC, Prins HJ, Gerrits J, Houthuijzen JM, Gerritsen MG, Schipper HS, Backer MJ, van Amersfoort M, Vermaat JS, Moerer P, Ishihara K, Kalkhoven E, Beijnen JH, Derksen PW, Medema RH, Martens AC, Brenkman AB, Voest EE: Mesenchymal stem cells induce resistance to chemotherapy through the release of platinum-induced fatty acids. Cancer Cell 2011, 20(3):370-383.

doi:10.1186/2045-3701-4-22

Cite this article as: Han et al:: Mesenchymal stem cells contribute to the chemoresistance of hepatocellular carcinoma cells in inflammatory environment by inducing autophagy. Cell \& Bioscience 2014 4:22.

\section{Submit your next manuscript to BioMed Central and take full advantage of:}

- Convenient online submission

- Thorough peer review

- No space constraints or color figure charges

- Immediate publication on acceptance

- Inclusion in PubMed, CAS, Scopus and Google Scholar

- Research which is freely available for redistribution 